\title{
O USO DE RECURSOS TECNOLÓGICOS COMO FACILITADORES NO ATENDIMENTO EDUCACIONAL ESPECIALIZADO COM PORTADORES DE BAIXA VISÃO
}

TAVARAYAMA, Rodrigo ${ }^{1}$

RESUMO: Em uma sociedade marcada pelo avanço do conhecimento e desenvolvimento de novas tecnologias em todas as áreas, a discussão acerca do uso das tecnologias assistivas na educação especial ganha destaque. O objetivo deste artigo foi realizar uma reflexão em torno do uso dos recursos tecnológicos na Educação Especial, especificamente no atendimento educacional especializado e a elaboração de um plano de aula orientado para o atendimento de alunos com baixa visão.

Palavras-Chave: Deficiência visual. Educação especial. Tecnologia assistiva. Novas tecnologias da informação e comunicação (TICs).

\section{USAGE OF TECHNOLOGICAL RESOURCES AS A SUPPORT ON EDUCATIONAL SERVICES SPECIALIZED IN VISUALLY IMPAIRED}

SUMMARY: In a society increasingly marked by advancement of knowledge and development of new technologies in all areas, the discussion around the use of assistive technology in special education is highlighted. The objective of this article was a reflection on the use of technological resources in Special Education, specifically in the the specialized educational services and preparing a lesson plan geared to the care of students with low vision.

Keywords: Visual impairment. Special education. Assistive technology. New Information and communication (TICs).

\section{INTRODUÇÃO}

\begin{abstract}
Para quem enxerga, é impossível imaginar a vida sem qualquer forma visual ou sem cor, porque as imagens e as cores fazem parte de nosso pensamento. Não basta fechar os olhos e tentar reproduzir o comportamento de um cego, pois tendo memória visual, a pessoa tem consciência do que não está vendo.
\end{abstract}

(BRASIL, 2000, p.8-9)

Em um mundo cada vez mais globalizado, com trocas de informações constantes e avanços tecnológicos, a educação se torna prioridade e a busca por um ensino de qualidade em todos os níveis é uma meta a ser alcançada por muitos países.

\footnotetext{
${ }^{1}$ Docente FE/FFCL/FAFRAM
} 
A importância dos novos recursos tecnológicos para o atendimento especializado de pessoas com cegueira e com baixa visão se torna um meio facilitador na aproximação, interação e participação de todos, com ou sem necessidades especiais neste novo contexto.

Alguns leigos acreditam que as novas tecnologias da informação e comunicação (TIC'S) seriam capazes por si só, de promover a informação, comunicação, interação, colaboração e na construção de novos conhecimentos, mas na verdade elas necessitam de um item fundamental que é a mediação.

Nesse sentido, a mediação torna-se necessária para o desenvolvimento das funções cognitivas dos indivíduos para que eles possam buscar na aprendizagem sua autonomia e construção do conhecimento, como também para sua independência, ou seja, cabe ao mediador viabilizar e criar um ambiente capaz de estimular a aprendizagem do aluno. Segundo Beck (2007):

$\mathrm{Na}$ Educação Especial, o uso do computador como ferramenta para o desenvolvimento de Pessoas com Necessidades Educacionais Especiais tem causado importantes avanços no âmbito educacional. O papel do professor também muda nesse contexto, passando de transmissor do conhecimento e dono da verdade absoluta para mediador, que motiva e incentiva os alunos a participarem do processo educativo (p.182).

Assim sendo, deve-se ter em mente que nenhum indivíduo é igual a outro e que cada um aprende de uma forma diferente, conforme a maneira que for melhor ou de sua preferência, o importante é que se possa motivar e facilitar a compreensão ou objeto de aprendizado (CAMPOS; SILVEIRA, 1998).

Os recursos tecnológicos facilitadores utilizados pelos deficientes também são conhecidos como tecnologias assistivas, como por exemplo, linguagem de sinais, textos de áudio, simuladores de teclado, sistema Braille e vocalizadores, os aparelhos eletrônicos possuem atualmente recursos que permitem aos deficientes auditivos interpretar vídeos, por meio da TV, DVD e legendas. A tecnologia assistiva vem ganhando atenção nos últimos tempos por parte de pesquisadores e educadores que defendem a importância do uso de tais recursos com o objetivo de suprir as necessidades dos indivíduos portadores de deficiências (ANSON, 2007; PELOSI, 2006; SORO-CAMATS, 2003; NUNES, 2007). Nesse sentido, a tecnologia assistida pode ser usada para melhoria de vida dos deficientes e idosos, resolução de problemas funcionais, redução de dependência e maior integração com a família e a sociedade (CAMPOS; SILVEIRA, 1998).

Podemos dar como exemplos alguns recursos tecnológicos utilizados pelos portadores de deficiência visual: o uso dos programas Dosvox e Vision ligados a impressoras multifuncionais que escaneiam os documentos e faz à leitura dos textos, outro recurso muito 
utilizado é o Perkins que serve para fazer as transcrições em Braille, o gravador digital, além do uso do Multiplano e Sorobam para a compreensão de conceitos matemáticos.

A tecnologia assistiva na educação deve contemplar o planejamento do professor a fim de proporcionar e favorecer o desenvolvimento das habilidades do aluno e que ele possa participar das atividades propostas sem ser excluído (ROCHA, 2010).

A comunicação assume nos casos de deficiências visuais papel fundamental para o processo de integração à sociedade, em todos os níveis. Para Beck (2007, p. 190-1) "a interação é essencial para a construção do conhecimento e que aprendemos à medida que experenciamos e agimos de maneira direta com o universo que nos rodeia e com as outras pessoas".

Segundo Monteiro (2010, p.7):

\begin{abstract}
O desenvolvimento de novas tecnologias para inclusão do deficiente visual está crescendo, inclusive no Brasil. São softwares e equipamentos conhecidos como "tecnologias específicas" que englobam ampliadores de telas que permitem, para pessoas de baixa visão, visualizar os elementos gráficos e textuais apresentados como a lupa eletrônica, a Lente de Aumento da Microsoft Windows, o Zoom da Ai Squared, o Magic da Freedom Scientific e o LentePro para usuários de baixa visão, o leitor autônomo que vê o documento, reconhece todo o texto e o lê para o usuário. Softwares leitores de tela como o sistema DOSVOX que se comunica com o usuário através de sintetizadores de voz, desenvolvido pelo Núcleo de Computação Eletrônica da Universidade Federal do Rio de Janeiro (NCE/UFRJ), o Jaws da Freedom Scientific e o Virtual Vision da MicroPower, que leem o conteúdo da tela do computador em voz alta. Impressoras Braille, impressoras de relevo, como por exemplo a Tiger Max. Scanners que digitaliza o documento e o converte em áudio como o Plustek BookReader entre outros.
\end{abstract}

No entanto, é preciso alertar que as pessoas com cegueira e baixa visão enfrentam dificuldades referentes ao acesso à informação e à comunicação, pela falta de recursos financeiros para adquiri-los e falta de escolas e professores capacitados (TORRES; MAZZOZI; MELLO, 2007; MIRANDA, 2002).

Segundo a autora Beck (2007, p.181):

O uso do computador e das tecnologias como proposta metodológica remete-nos a refletir sobre nossa própria caminhada enquanto educadores e formadores de opiniões. Sabemos a importância que o aluno atribui à imagem do professor e, para tanto, precisamos buscar uma atualização constante, refletindo sobre nossa docência.

Como falar de excelência na qualidade do ensino quando ainda não conseguimos erradicar problemas como a fome e a exclusão social? Como falar em inclusão social efetiva enquanto ainda há falta de recursos, infraestruturas e professores capacitados para a mediação do ensino-aprendizagem? São muitos os desafios no atual contexto.

Com certeza a escola de hoje não é a mesma de décadas e anos atrás, mas ainda perpetua a reprodução de ideologias de uma classe dominante e excludente, sem contar a falta de uma escola de qualidade e acessível para todos, conforme garante a Constituição Brasileira 
de 1988. No entanto, não podemos ignorar alguns avanços nos últimos anos no campo da ciência, na utilização e aplicação de recursos tecnológicos e facilitadores para os portadores de deficiência visual.

Durante muito tempo criou-se uma imagem errada a respeito das crianças portadoras de deficiência visual, no entanto:

\begin{abstract}
As crianças com deficiência visual não são muito diferentes das outras crianças, têm as mesmas necessidades afetivas, físicas, intelectuais, sociais e culturais. As necessidades básicas das demais crianças: atenção, cuidado, relação e interação positiva, afeto e segurança são essenciais para as crianças com deficiência visual (BRASIL, 2006, p.13).
\end{abstract}

O desenvolvimento deste artigo teve dois objetivos, o primeiro foi de realizar uma reflexão em torno dos recursos tecnológicos aplicados no atendimento educacional especializado com portadores de deficiência visual e o segundo foi de elaborar um plano de aula hipotético para o atendimento de uma criança portadora de baixa visão, demonstrando as possibilidades do uso de recursos no ensino-aprendizagem, bem como a adaptação de métodos e recursos no atendimento educacional.

\title{
REFERENCIAL TEÓRICO
}

Pautando-se no princípio de que a educação inclusiva é a busca por um ambiente escolar e social menos restritivo e mais acolhedor. A educação inclusiva tem suas bases na Convenção de Direitos da Criança de 1988, na Declaração sobre Educação para todos de 1990 e na Declaração de Salamanca de 1994, documentos esses que visão a inclusão social e a implantação de uma educação inclusiva.

O presente trabalho utilizou como referencial teórico a teoria crítico-dialética aplicada à educação com objetivo de compreender, analisar e refletir sobre a questão do uso da tecnologia na educação especial, especificamente no trabalho de ensino-aprendizagem com portadores de baixa visão.

A análise das práticas bem como do contexto em que é envolvida tanto a escola quanto o aluno são importantes para traçar o planejamento das atividades a fim de adaptá-las as necessidades de cada aluno de acordo com a infraestutura e recursos disponíveis na escola. A teoria crítico-dialética fundamenta-se na análise do contexto social envolvido, bem como a influência de fatores externos e internos (GADOTTI, 2003), na análise da educação especial não podemos de considerar que a educação sofre uma influência direta do Estado e que por trás está uma lógica econômica capitalista muito forte que acaba interferindo diretamente na educação. Nesse sentido destacamos a importância da teoria crítico-dialética, segundo 
Frigotto (1994, p.75), “a dialética situa-se, então, no plano de realidade, no plano histórico, sob a forma da trama de relações contraditórias, conflitantes, de leis de construção, desenvolvimento e transformação dos fatos".

Nesse sentido, não basta somente interpretar a realidade, mas também trabalhar para transformá-la, propondo mudanças, soluções e melhorias, levando em conta ainda a totalidade, o específico, o singular e o particular (FRIGOTTO, 1994).

Compreender o verdadeiro sentido da palavra ensinar significa perceber que não há uma única forma ou modelo para isso, cabendo a cada professor criar alternativas metodológicas e adaptá-las à realidade de cada aluno, sabendo aproveitar ao máximo os recursos disponíveis (BECK, 2007).

\section{METODOLOGIA}

O presente trabalho procurou realizar uma reflexão em torno da questão do uso da tecnologia no atendimento educacional especializado com portadores de baixa visão, para isso utilizou-se da técnica de pesquisa de revisão bibliográfica.

Segundo Severino (2007):

A pesquisa bibliográfica é aquela que se realiza a partir di registro disponível, decorrente de pesquisas anteriores, em documentos impressos, como livros, artigos, teses etc. Utiliza-se de dados ou categorias teóricas já trabalhados por outros pesquisadores e devidamente registrados. Os textos tornam-se fontes dos temas a serem pesquisados. O pesquisador trabalha a partir das contribuições dos autores dos estudos analíticos constantes dos textos (p.122).

Após analisar e discutir o uso de recursos tecnológicos como facilitadores no processo de ensino-aprendizagem e inclusão social dos portadores de deficiência visual, foi elaborado um plano de aula hipotético com recursos que poderiam ser utilizados com determinado aluno com baixa visão.

\section{PLANO DE AULA ORIENTADO PARA ATENDIMENTO DE UM ALUNO DE BAIXA VISÃO COM DIFICULDADES}

Ao elaborar um planejamento para atender um aluno portador de deficiência visual é preciso conhecer o seu grau de dificuldade, suas preferências, a questão do ambiente, iluminação e particularidades (estas coletadas junto à família e a outros professores).

No atendimento educacional especializado voltado aos portadores de deficiência visual é necessário também que se identifiquem os motivos e as causas do problema de cada aluno. As causas mais freqüentes da cegueira e visão subnormal, então podem ser: 
- Retinopatia da prematuridade causada pela imaturidade da retina, em decorrência de parto prematuro ou de excesso de oxigênio na incubadora;

- Catarata congênita em conseqüência de rubéola ou de outras infecções na gestação;

- Glaucoma congênito que pode ser hereditário ou causado por infecções;

- Atrofia óptica.

- Degenerações retinianas e alterações visuais corticais;

- Diabetes, descolamento de retina ou traumatismos oculares (BRASIL, 2000, p.9).

Deve-se levar em consideração que "os graus de visão abrangem um amplo espectro de possibilidades: desde a cegueira total, até a visão perfeita, também total. A expressão deficiência visual se refere ao espectro que vai da cegueira até a visão subnormal" (BRASIL, 2000, p.6).

As dificuldades visuais que as crianças podem apresentar são:

a) Acuidade visual reduzida: a criança apresenta dificuldade para ver de longe, precisa aproximar-se bastante para poder ver bem pessoas e objetos, mesmo que utilize recursos ópticos. Muitas crianças podem apresentar dificuldades para encontrar objetos, descrever figuras, definir detalhes, formas complexas, identificar cores, letras, ler, escrever e desenhar como as outras crianças.

b) Campo visual restrito: uma criança que enxerga bem tem um campo visual de 180 graus na horizontal e vertical, o que possibilita interagir, localizar-se e orientar-se bem no ambiente. Já as crianças com baixa visão, dependendo do tipo de problema visual, podem possuir um campo visual bastante restrito, o que pode prejudicar sua orientação e locomoção no espaço. O campo visual pode ser alterado em diferentes posições. Há crianças que não enxergam para baixo, e terão, por isso, dificuldade para andar, descer e subir escadas e se desviar de obstáculos. Outras apresentam alteração no campo visual central, o que dificultará o processo de identificação de figuras; elas poderão ver apenas uma pequena parte de um objeto ou quadro; a leitura torna-se difícil e lenta. As alterações de visão periférica prejudicam a visão espacial, a percepção de obstáculos e a locomoção independente.

c) Visão de cores e sensibilidade aos contrastes: há algumas alterações visuais nas quais as crianças são incapazes de distinguir determinadas cores como verde, vermelho, azul, marrom; outras crianças distinguem cores vibrantes, com bastante luminância (amarelo, laranja e verde fluorescente). Há crianças que podem ver objetos, formas e letras com bastante contraste (preto/branco, amarelo/preto, amarelo/azul, roxo/verde e laranja/verde). O professor deve pesquisar, juntamente com a família, quais as cores que despertam interesse nas crianças e com as quais elas podem visualizar melhor.

d) Adaptação à iluminação: algumas crianças com baixa visão podem apresentar sensibilidade exagerada à luz, que ocasiona desconforto visual, ofuscamento, irritabilidade, lacrimejamento, dor de cabeça e nos olhos. O controle dos índices de iluminação no ambiente e a utilização de lentes filtrantes são importantes para melhora das respostas e conforto visual destas crianças. Há, entretanto, crianças que necessitam de muita iluminação e luz dirigida aos objetos para que possa enxergar melhor (BRASIL, 2006, p.14).

Nesse sentido, elaboramos um plano hipotético para o atendimento de um aluno com baixa visão, neste caso, o primeiro passo é colher informações junto à família e a outros professores para poder traçar o planejamento. Após esse levantamento e coleta de dados, ao verificar que se trata de um aluno com baixa visão, e, portanto não portador de cegueira, as 
atividades e metodologias serão adequadas para o seu caso em particular, lembrando sempre que os casos de deficiência visual não são todos iguais.

Mas, o que seria um aluno com baixa visão?

A definição de baixa visão (ambliopia, visão subnormal ou visão residual) é complexa devido à variedade e à intensidade de comprometimentos das funções visuais. Essas funções englobam desde a simples percepção de luz até a redução da acuidade e do campo visual que interferem ou limitam a execução de tarefas e o desempenho geral (BRASIL, 2007, p.16).

Definido o conceito de baixa visão podemos iniciar nosso planejamento e estratégias. Nesse sentido é importante que seja analisado o caso particular do aluno a fim de inteirar-se do caso. As causas mais freqüentes dos problemas de deficiência do campo visual na infância podem ser:

- Coriorretinite por toxoplasmose congênita (infestação pelo protozoário Gondi na gestação);

- Catarata por síndrome da rubéola congênita (mãe adquire rubéola na gestação);

- Retinopatia por prematuridade, hemorragias e lesões vasculares;

- Malformações oculares, encefalopatias e síndromes;

- Atrofia óptica por infecções, vírus, bactérias, alterações no sistema nervoso central por anóxia ou hipóxia, meningite, encefalite e hidrocefalia, e

- Deficiência visual cortical pelas causas já citadas, drogas de todos os tipos e quadros convulsivos (BRASIL, 2006, p.14-15).

A respeito da questão do ambiente, se tratando de um aluno com baixa visão, ele deve ser bem iluminado, no caso colocando-o o aluno próximo a janela ou adaptando uma luminária em sua mesa para que possa enxergar os contrastes, o material deve ser também adaptado os cadernos e apostilas devem ser com letras maiores e cores escuras com plano claro, ou vice-versa, e utilização de lupas para aumentar o campo de visão.

Outro recurso que pode ser utilizado pode ser a gravação da aula em um aparelho de gravar digital para que depois o aluno possa ouvir a aula e as explicações do professor.

Imaginando uma situação de aprendizagem com ilustração, por exemplo, em uma aula de ciências cujo conteúdo seja elementos da flora e fauna, pode-se reproduzi-lo com material do tipo EVA, canudos e legendas em Braille.

Como parte do processo de mediação, o professor pode escolher alunos que serão mediadores na sala de aula, a fim de ajudar o aluno com deficiência visual (DV), esta situação tem dois pontos importantes, que é a socialização e o exercício da cidadania, mas é claro que tal metodologia deve ser antes trabalhada com a sala de aula para esclarecimento de dúvidas e evitar possíveis problemas futuros. Pois, a proposta de inclusão suscita vários problemas, pois envolve crenças, valores, conceitos e preconceitos.

Como todo o trabalho será acompanhado por um especialista e este ficará incumbido de analisar se as práticas estão surtindo efeito, caso contrário buscar alternativas diferentes. É 
um processo dialético que necessita a todo o momento de reflexão e adaptação a novas situações.

As tecnologias assistivas como o uso do computador, o sistema Braille e softwares educacionais de voz devem também ser estimulados no dia-a-dia do deficiente visual (DV), pois são ferramentas que possibilitarão uma maior independência e consequentemente motivação em aprender. Pois entendemos que "as atividades realizadas devem proporcionar prazer e motivação, o que leva à intencionalidade e esta desenvolve a iniciativa e a autonomia, que são os objetivos primordiais da estimulação visual" (BRASIL, 2007, p.18).

$\mathrm{Na}$ falta de recursos tecnológicos e a dificuldade de acesso a informação e à comunicação nas escolas, é fundamental que o professor/mediador esteja atento à necessidade da intervenção e está deve ser orientada por três aspectos:

1. A pessoa que emite a mensagem precisa estar ciente das suas responsabilidades para o processo da acessibilidade;

2. O receptor da mensagem, por sua vez, deve estar familiarizado com o ambiente, as ajudas técnicas e o apoio humano com o qual irá contar nesse ambiente e precisa estar preparado para saber apresentar as suas reivindicações;

3. O ambiente no qual ocorre o processo de comunicação deve ser tal que permita a transmissão da informação de forma redundante, devendo-se utilizar, para tanto, as técnicas de transformação da informação, associadas com o uso de ajudas técnicas, e as diversas formas de apoio humano (como as pessoas que lêem em voz alta, as que retransmitem as palavras silenciosamente articulando-as corretamente; as que interpretam as frases e as transmitem em línguas de sinais; as que retransmitem as palavras estimulando de forma tátil ao receptor da mensagem etc.) (TORRES; MAZZONI; MELO, 2007, p.382-383).

A elaboração e planejamento das atividades, bem como as escolhas de metodologias e recursos variam de acordo com a realidade e do grau de deficiência visual de cada indivíduo, e muitas vezes pela falta de infraestrutura das escolas e dificuldades financeiras em adquirir os recursos tecnológicos pela família e pela própria escola.

Todo o trabalho de abordagem pedagógica deve ter como foco:

- Escutar e acolher a criança e seus familiares;

- Trabalhar a partir das possibilidades e potencialidades da criança, tendo em vista o desenvolvimento integral;

- Atender às necessidades específicas no contexto familiar e escolar;

- Apoiar a relação dialógica e interações positivas mãe-criança, criança-criança, mãe-mãe;

- Respeitar as prioridades, os pontos de vista e a cultura das famílias;

- Valorizar os elementos psicoafetivos pela interação em brincadeiras e jogos sociais em grupo;

- Desenvolver o programa em pequenos grupos, valorizando o brincar, a troca de experiência e a construção coletiva do conhecimento entre crianças e familiares;

- Privilegiar atividades lúdicas de interação, comunicação, artes, cultura, lazer e recreação, e

- Mobilizar a comunidade para atitudes positivas e apoio comunitário às crianças e familiares. (BRASIL, 2006, p.33). 
O uso da tecnologia na Educação Especial desempenha um papel importante para o desenvolvimento afetivo, cognitivo e sociocultural dos sujeitos, bem como o direto de ser diferente e ao mesmo dependente e independente, dependente sim da tecnologia, mas independente na maneira de agir, compreender e interagir com o mundo a sua volta. Segundo Fonseca (1987):

\footnotetext{
O deficiente é uma pessoa com direitos. Existe, sente, pensa e cria. Tem uma limitação corporal ou mental que pode afetar aspectos de comportamento, aspectos estes muitas vezes atípicos, uns fortes e adaptativos, outros fracos e pouco funcionais, que lhe dão um perfil intra-individual peculiar. Possui igualmente discrepâncias no desenvolvimento biopsicossocial, ao mesmo tempo que aspira a uma relação de verdade e de autenticidade e não a uma relação de coexistência conformista e irresponsável (p.11).
}

Um ambiente inclusivo tem sua essência baseada no direito de todas as pessoas o direito de participação, de poder viver uma tão normal quanto possível, sem ser discriminado e onde tenha assegurada a sua igualdade de oportunidades. Ressalta-se ainda a importância da inclusão do aluno com baixa visão desde cedo à escola para que ele possa desenvolver suas habilidades o mais cedo possível.

\section{CONSIDERAÇÕES FINAIS}

Ao final deste artigo, pode-se analisar que ainda falta uma maior preparação das escolas e dos professores para atender e trabalhar com os alunos portadores de necessidades especiais.

A idéia de uma escola democrática não se resume somente a oferecer o ensino para todos, mas sim de oferecer um ensino de qualidade e garantir o pleno exercício da cidadania adaptando tanto a escola como os conteúdos, não basta oportunizar o acesso e a permanência na escola para todos, pois o direito à educação implica o direito de aprender na escola (GADOTTI, 2005).

Em um contexto marcado pelos avanços tecnológicos a educação assume papel ímpar, nesse sentido ensinar não é somente questão de transferir conhecimento, mas criar possibilidades para sua própria produção ou a sua construção (FREIRE, 2005).

O uso de tecnologias assistivas no processo de ensino-aprendizagem de portadores de baixa visão vem ganhando atenção de pesquisadores e educadores, no entanto ainda encontram barreiras a serem enfrentadas como a falta de material, infraestrutura e condições sócio-econômicas. 
É importante lembrar que somente a inclusão do aluno portador de necessidades especiais e o fornecimento de tecnologia assistiva não são garantias para que o processo de ensino-aprendizagem se realize de forma plena (ROCHA, 2010).

Em um país como o Brasil onde o acesso ao conhecimento é ainda muito precário (GADOTTI, 2005), o que dizer sobre o acesso a educação para os portadores de deficiência? Os portadores de deficiência necessitam e tem o direito garantido por lei a recursos especiais para o desenvolvimento de suas potencialidades, de se expressarem, de se comunicarem, de serem independentes e de terem sua dignidade respeitada. Mas em muitos casos o que mais preocupa é a falta de interesse por parte dos Estados em relação ao atendimento desses alunos, o discurso continua o mesmo, o da luta pela equiparação de oportunidades e diminuição da exclusão social, mas é o que mais tem acontecido é o descaso e o aumento da exclusão no país.

Os desafios ainda são muitos, a tecnologia aplicada à educação representa para o portador de necessidades educacionais especiais mais do que o direito a acessar a rede de informações, mas de romper barreiras, sejam elas físicas, sociais, intelectuais, culturais e políticas. Não basta somente interpretar a realidade, mas também preciso transformá-la. Lidar com o diferente representa um processo de desconstrução o que requer redescobrir caminhos, indo de encontro aos preconceitos e, além disso, respeitar o outro na diferença, a idéia de uma escola inclusiva exige mudanças de ordens individuais e coletivas e uma mudança no paradigma educacional.

\section{REFERÊNCIAS}

ANSON, D. Tecnologia assistiva. In PEDRETTI; L. W.; EARLY, M. B. Terapia ocupacional: capacidades práticas para as disfunções físicas. 5 ed. São Paulo: Roca, 2005. p. $276-295$.

BECK, F. L. A informática na educação especial: interatividade e representações sociais. In: Cadernos de Educação, FaE/PPGE/UFPel, n. ${ }^{\circ} 28$, janeiro/junho, 2007. p.175-196. Disponível em: <http://www.ufpel.edu.br/fae/caduc/downloads/n28/artigo07.pdf>. Acesso em: 11/05/2011.

BRASIL, Ministério da Educação. Deficiência Visual. In: GIL, M. (org). Cadernos da TV Escola. Ministério da Educação, Secretaria de Educação a Distância. n. ${ }^{\circ} 1 / 2000$. Disponível $\mathrm{em}:<$ http://www.dominiopublico.gov.br/download/texto/me000344.pdf $>$. Acesso em: $12 / 05 / 2011$. 
BRASIL, Ministério da Educação. Formação Continuada a Distância de Professores para o Atendimento Educacional Especializado: Deficiência Visual. In: SEESP / SEED / MEC. Brasília, 2007. Disponível em: $<$ http://portal.mec.gov.br/seesp/arquivos/pdf/aee dv.pdf $>$. Acesso em: 11/03/2011.

BRASIL, Ministério da Educação. Dificuldades de comunicação e sinalização: Deficiência Visual. In: Educação Infantil: saberes e práticas de inclusão. Brasília, 2006. Disponível em: $<$ http://portal.mec.gov.br/seesp/arquivos/pdf/deficienciavisual.pdf>. Acesso em: 12/05/2011.

CAMPOS, M. de B.; SILVEIRA, M. S. Tecnologias para educação especial. In: IV Congresso RIBIE, Brasília, 1998. Disponível em:

<http://www.url.edu.gt/sitios/tice/docs/trabalhos/167.pdf>. Acesso em: 10/05/2011.

FONSECA, V. Educação Especial. Porto Alegre: Artes Médicas, 1987.

FREIRE, P. Pedagogia do Oprimido. Rio de Janeiro: Paz e Terra, 2005.

FRIGOTTO, G. O Enfoque da dialética materialista histórica na pesquisa educacional. In: FAZENDA, Ivani (Org.). Metodologia da pesquisa educacional. São Paulo: Cortez, 1994. p.69-90.

GADOTTI, M. Concepção dialética da educação: um estudo introdutório. $13^{\circ}$ Edição. São Paulo: Cortez, 2003.

Informação, conhecimento e sociedade em rede: que potencialidades? In: Revista

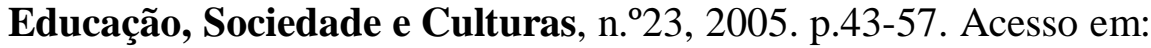

<http://www.fpce.up.pt/ciie/revistaesc/ESC23/23-Moacir.pdf>. Acesso em: 10/05/2011.

MIRANDA, A. da S. Recomendações de acessibilidade digital em cursos de educação a distância via web para portadores de deficiência visual. Dissertação de Mestrado em Ciência da Computação pelo Centro Tecnológico, Universidade Federal de Santa Catarina, Florianópolis, 2002.

MONTEIRO, E. C. de S. de A. O serviço de referência e a acessibilidade aos deficientes visuais. In: XVI Seminário Nacional de Bibliotecas Universitárias e II Seminário Internacional de Bibliotecas Digitais. UFRJ, Rio de Janeiro, 2010. p. 1-12. Disponível em: <http://www.sibi.ufrj.br/snbu/pdfs/orais//final_387.pdf>. Acesso em: 13/03/2011.

NUNES, L. R. O. P. Um Breve Histórico da Pesquisa da Comunicação Alternativa na UERJ. In: NUNES, L. R. O. P; PELOSI, M. B.; GOMES, M. R. (Orgs.). Um Retrato da Comunicação alternativa no Brasil - Relato de Pesquisas e experiências. Volume II. Rio de Janeiro: 4 Pontos Estúdio Gráfico e Papéis, 2007. p.19-32.

PELOSI, M. B. Por uma escola que ensine e não apenas acolha: recursos e estratégias para a inclusão escolar. In MANZINI, E. J. Inclusão e Acessibilidade. Marília: ABPEE, 2006. p.121-132.

ROCHA, A. N. D. C. Processo de prescrição e confecção de recursos de tecnologia assistiva para educação infantil. Dissertação de Mestrado do Programa de Pós-Graduação em Educação. Universidade Estadual Paulista, Faculdade de Filosofia e Ciências, Marília, 2010. Disponível em: $<$ http://www.marilia.unesp.br/Home/Pos-

Graduacao/Educacao/Dissertacoes/rocha_andc_me_mar.pdf>. Acesso em: 11/05/2011. 
SEVERINO, A. J. Metodologia do trabalho científico. 23a Edição. São Paulo: Cortez, 2007.

SORO-CAMATS, E. Uso de ajudas técnicas para a comunicação, o jogo, a mobilidade e o controle do meio: uma abordagem habilitadora. In: ALMIRALL, C. B.; SORO-CAMATS, E.; BULTÓ, C. R. (Org.). Sistemas de sinais e ajudas técnicas para a comunicação alternativa e a escrita: princípios teóricos e aplicações. São Paulo: Livraria Santos Editora, 2003. p. 23-41.

TORRES, E. F.; MAZZONI, A. A.; MELLO, A. G. de. Nem toda pessoa cega lê e nem toda pessoa surda se comunica em língua de sinais. In: Revista Educação e Pesquisa, São Paulo, v.33, n.2, maio/ago, 2007. p.369-385. Disponível em:

<http://www.bancodeescola.com/a13v33n2.pdf >. Acesso em: 11/05/2011. 